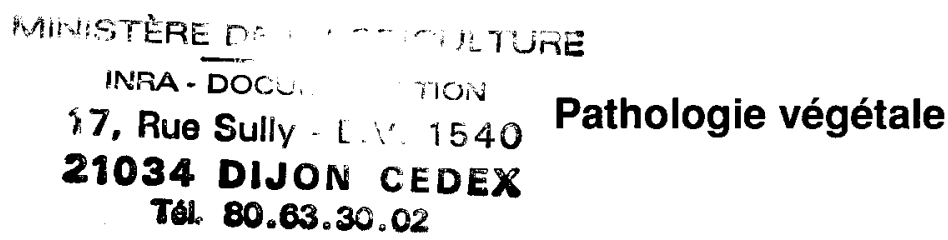

\title{
Étude en microscopie électronique à balayage de l'installation de deux souches de Xanthomonas campestris pv manihotis sur feuilles de vitroplants de manioc
}

\author{
V Verdier ${ }^{1^{*}}, \mathrm{~J} \mathrm{Schmit}^{2}$, M Lemattre ${ }^{2}$ \\ 1 ORSTOM, Laboratoire de phytopathologie, BP 181, Brazzaville, Congo ; \\ 2 INRA, Station de pathologie végétale, Route de St-Cyr, 78026 Versailles Cedex, France
}

(Reçu le 28 avril 1989 ; accepté le 8 novembre 1989)

\begin{abstract}
Résumé - L'installation de 2 souches de Xanthomonas campestris pv manihotis, agressive (XCM17) et non agressive (XCM4), est suivie conjointement par numération et par microscopie électronique à balayage, sur des vitroplants de manioc. Les observations réalisées en microscopie électronique à balayage confirment la dynamique de population des 2 souches et permettent aussi de localiser les bactéries à la surface des tissus. Immédiatement après inoculation, l'aspect et la répartition des bactéries à la surface du limbe sont identiques quelle que soit la souche. Six jours après inoculation, la souche non agressive (XCM4) qui ne se multiplie pas ou peu à la surface du limbe n'entraîne pas d'altération des tissus foliaires. L'observation décèle la présence d'un voile recouvrant les cellules bactériennes. Dans les mêmes conditions, la souche agressive (XCM17) se multiplie rapidement; on note la présence d'amas bactériens à proximité des stomates et les tissus présentent des altérations importantes.

La méthode d'inoculation mise au point sur vitroplants de manioc permet de reproduire les symptômes caractéristiques de la maladie et de retrouver le comportement attendu des variétés utilisées. La culture in vitro fournit un matériel commode pour l'étude par différentes techniques des premières étapes de l'infection.
\end{abstract}

Manihot esculenta / bactériose vasculaire / culture de tissus / phase épiphyte

Summary - Scanning electron microscopic study of the establishment of 2 strains of Xanthomonas campestris pv manihotis on in vitro microcuttings of cassava. The establishment of 2 strains of Xanthomonas compestris pv manihotis (XCM 17: aggressive; XCM 4: non-aggressive) on vitroplants of cassava was monitored by counting and by scanning electron microscopy (SEM). Each strain differed in its establishment following leaf inoculation. Aggressive strain XCM 17 multiplied rapidly, whereas non aggressive strain XCM 4 maintained its initial population level (fig 1). Moreover, only the aggressive strain was detected at increasing levels in leaf tissues 4 days after inoculation (fig 2).

SEM examinations confirmed the population dynamic patterns of the 2 strains. In addition, the localization of bacterial cells and their spreading on the leaf surface were more accurately defined. Two methods were used to process samples: examination in fresh state with a "cryoscan" device and after glutaraldehyde-OsO $\mathrm{O}_{4}$ fixation followed by critical point drying. Both methods maintained structural organization of samples, but "cryoscan" gave better preservation of plant tissues (figs 3 and 4), than critical point drying (figs 5 and 6). The reverse was observed for bacterial cells (figs 7 and 8). Comparing both methods, thus helped to avoid major misinterpretations.

Immediately after inoculation, the appearance and the distribution of bacteria were similar for both strains (figs 9 and 10). Within 6 days the non-aggressive strain (XCM 4) which multiplied slightly or not at all, did not lead to visible alterations in leaf tissues (figs 17a and b). SEM revealed bacterial cells trapped under a thin layer of unknown composition (figs 16a and b). Under similar conditions, the aggressive strain (XCM 17) increased rapidly (figs 11 and 12). Masses of bacteria were visible near stomata (figs $13,14,15)$ and well-marked lesions developed on leaves (figs 18a and $b ; 19 a$ and $b$ ).

In agreement with other studies, our results suggest the relative importance of colonization of stomata and their surroundings in aerial bacterial infection. Here a correlation was found between strain aggressivity and colonization of cassava leaves.

Adopting the inoculation method on vitroplants as proposed here, we were able to observe the typical symptoms of the disease and the expected behaviour of a variety of cassava. In vitro culture provides a material suitable for studying several steps of host-pathogen interactions by different experimental techniques.

Manihot esculenta / cassava bacterial blight / tissue culture / epiphytic phase

* Correspondance et tirés à part 


\section{INTRODUCTION}

La phase épiphylle de Xanthomonas campestris pv manihotis, phase pendant laquelle la bactérie survit et se multiplie en surface de l'hôte avant pénétration dans les tissus du limbe, a d'importantes implications dans l'épidémiologie de la bactériose (Daniel et Boher, 1978; Persley, 1978 ; Daniel et Boher, 1985). L'agent pathogène se propage ensuite dans les tissus vasculaires (Lozano et Sequeira, 1974 ; Perreaux et al, 1978). Néanmoins, dans l'infection à Xanthomonas campestris pv manihotis la bactérie peut être détectée dans les tiges de plants apparemment sains et la bouture infectée est, par conséquent, un des modes de transmission principaux de la maladie (Boher et Daniel, 1982 ; Kwage, 1982).

Les techniques de culture in vitro ont été utilisées pour étudier certaines étapes de l'interaction hôte-parasite en conditions parfaitement contrôlées (Schmit, 1978; Maas et al, 1985; Rott et Chagvardieff, 1987 ; Brisset et al, 1988 ; Hammerschlag, 1988). Néanmoins ces systèmes simplifiés ne prétendent pas représenter les conditions microbiologiques, physiologiques et climatiques de l'environnement naturel. Dans les travaux présentés ici, l'installation de 2 souches, agressive et non agressive, de $X c \mathrm{pv}$ manihotis est étudiée en axénie sur vitroplants et précisée parallèlement par une observation en microscopie électronique à balayage.

\section{MATÉRIELS ET MÉTHODES}

\section{Matériel végétal}

La variété de manioc, TMS 30555, utilisée dans cette étude est originaire du Nigéria (lita, 1983). Elle est mentionnée comme tolérante à la bactériose et à la mosaïque. En République Populaire du Congo, son emploi est croissant dans les zones de culture du manioc. II a été montré in vivo (Maraite et al, 1981) et in vitro (Verdier, 1988) que sa résistance est indépendante de la colonisation des tissus foliaires. En revanche, la propagation de l'agent pathogène dans les tissus vasculaires est limitée. Les vitroplants sont obtenus selon les techniques classiques de microbouturage in vitro (Mabanza et Jonard, 1981). Le milieu de base utilisé est celui de Murashige et Skoog (1962) supplémenté en saccharose $\left(30{\mathrm{~g} . \mathrm{I}^{-1}}^{-1}\right.$, myo-inositol (100 mg. $\left.\mathrm{l}^{-1}\right)$, agar $\left(7 \mathrm{~g} . \mathrm{I}^{-1}\right)$, le $\mathrm{pH}$ est ajusté à 5,6-5,8. L'hormone de croissance est ajoutée après autocla-

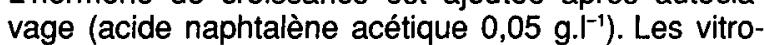
plants sont placés en chambre climatique, à $28^{\circ} \mathrm{C}$, sous un éclairement de 3000 lux et une photopériode de $16 \mathrm{~h}$ de jour et $8 \mathrm{~h}$ de nuit.

\section{Inoculum}

Deux souches de Xanthomonas campestris pv manihotis sont utilisées dans cette étude, la souche XCM4, originaire de Colombie, non agressive et la souche $\mathrm{XCM} 17$, originaire du Congo, agressive sur plusieurs variétés testées (Grousson, 1986 ; Verdier, 1988). Les bactéries sont cultivées sur milieu LPGA (extrait de levure $5 \mathrm{~g}$, bactopeptone $5 \mathrm{~g}$, glucose $5 \mathrm{~g}$, agar $15 \mathrm{~g}$, eau distillée qsp $1000 \mathrm{ml}, \mathrm{pH}$ 7) pendant $48 \mathrm{~h}$ puis lavées 2 fois avec un tampon phosphate stérile $\left(\mathrm{NaCl} 7,2 \mathrm{~g} ; \mathrm{Na}_{2} \mathrm{HPO} 42,79 \mathrm{~g} ; \mathrm{KH}_{2} \mathrm{PO} 43,25 \mathrm{~g}\right.$; $\mathrm{pH} 7,2$ ) et centrifugées à $8000 \mathrm{~g}$ pendant $10 \mathrm{~min}$. Les suspensions bactériennes sont préparées dans l'eau distillée stérile à une concentration de $10^{8}$ (ufc). $\mathrm{mL}^{-1}$ d'après une courbe de référence (densité optique-bactéries viables) établie par numération sur boîtes.

\section{Inoculation des plants}

Les inoculations sont réalisées en condition stérile sur vitroplants racinés âgés de 6 semaines (stade 3-4 feuilles développées). L'inoculum calibré à $10^{8}$ (ufc). $\mathrm{mL}^{-1}$ est déposé au pinceau à la face supérieure et inférieure des 2 premières feuilles développées (les plus âgées). Les plants témoins sont traités à l'eau distillée stérile dans les mêmes conditions. Après inoculation les vitroplants sont replacés en chambre climatique dans les conditions précédemment décrites.

\section{Détermination des populations bactériennes}

Immédiatement après inoculation puis $1,2,4,6,8$, 10 j après, on prélève aseptiquement sur chaque vitroplant les 2 feuilles inoculées. Les limbes sont placés en agitation dans l'eau distillée stérile additionnée de Tween $80(0,01 \%$, dose démontrée non toxique sur nos 2 souches) pendant $2 \mathrm{~h}$. Un dénombrement des bactéries est effectué sur cette eau de lavage. Les limbes sont ensuite désinfectés dans l'hypochlorite de sodium $(3 \%)$ pendant $30 \mathrm{~s}$, rincés 3 fois puis broyés dans $3 \mathrm{ml}$ d'eau stérile. La désinfection tue les bactéries en surface. La concentration bactérienne dans les lavages et broyages des tissus est évaluée par la technique des suspensions dilutions et numérations sur boîtes après incubation $48 \mathrm{~h}$ à $30^{\circ} \mathrm{C}$, et rapportée au $\mathrm{cm}^{2}$ de feuille.

\section{Traitement statistique}

Pour chaque interaction souche $x$ variété étudiée, 100 vitroplants sont inoculés. On fait 9 répétitions pour chaque observation (2 feuilles). Pour comparer les valeurs des moyennes des populations bactériennes à la surface des feuilles, nous avons utilisé le test de Student (Schwartz, 1969).

\section{Microscopie électronique à balayage}

Les 2 premières feuilles développées (inoculées et témoins) sont prélevées et découpées stérilement en fragments d'environ $1 \mathrm{~cm}^{2}$ (10 échantillons) aux temps 
0,2 et 6 jours après inoculation. Les échantillons sont observés selon 2 méthodes différentes, à l'état hydraté (dispositif cryoscan) et après déshydratation selon la méthode du point critique. Dans le $1^{\mathrm{er}}$ cas, les tissus, congelés à l'état frais dans du fréon (refroidi par de l'azote liquide) puis métallisés immédiatement sous vide dans un sas adjacent à la colonne du microscope, sont introduits dans celle-ci et observés. Dans le $2^{\mathrm{e}}$ cas, les échantillons sont fixés pendant $2 \mathrm{~h}$ à $4{ }^{\circ} \mathrm{C}$ dans une solution de glutaraldéhyde à $4 \%$ dans un tampon phosphate $(25 \mathrm{mM}, \mathrm{pH} 6,5)$ puis, après 6 lavages dans le tampon, post-fixés $1 \mathrm{~h}$ dans une solution de tétroxyde d'osmium à $1 \%$. Les tissus déshydratés par l'éthanol $\left(30^{\circ}, 50^{\circ}, 70^{\circ}, 95^{\circ},\left(3 \times 100^{\circ}\right)\right)$ puis par l'acétone pur anhydre sont séchés, selon la méthode du point critique (fluide intermédiaire: dioxyde de carbone) et métallisés à l'or sous vide. Le microscope utilisé est un Jeol JSM 35, opérant à 20 kV.

\section{RÉSULTATS}

\section{Dynamique des populations}

Sur tous les vitroplants inoculés avec la souche agressive on observe, 4 à $5 \mathrm{j}$ après inoculation, l'apparition de taches translucides sur les feuilles, évoluant en petites plages nécrotiques. Tous les vitroplants inoculés avec la souche non agressive ne présentent aucune lésion, ce qui confirme les observations faites sur plantes en pots (Grousson, 1986).

Le nombre de bactéries à la surface des feuilles varie au cours du temps (fig 1). Cette évolution est très différente pour les 2 souches. La souche agressive (XCM17) se multiplie rapidement alors que la souche non agressive (XCM4) se maintient à son niveau d'origine. La comparaison des moyennes du nombre de bactéries à la surface des feuilles montre une différente significative entre les 2 souches.

La souche non agressive (XCM4) n'a pas été détectée dans les broyats de feuilles. En revanche la souche agressive (XCM17) y est détectée à partir du $4^{\mathrm{e}}$ jour après inoculation et s'y multiplie rapidement (fig 2). Les prélèvements avant le $4^{\mathrm{e}}$ jour sont négatifs.

\section{Microscopie électronique à balayage}

\section{Morphologie des tissus sains et des cellules bactériennes}

Au cryoscan, sur tissus frais, l'aspect et l'organisation des surfaces foliaires apparaissent bien conservés. A la face supérieure, les tissus sont constitués de cellules épidermiques d'aspect lisse et bombé. Elles présentent au niveau des nervures une forme allongée et un revêtement

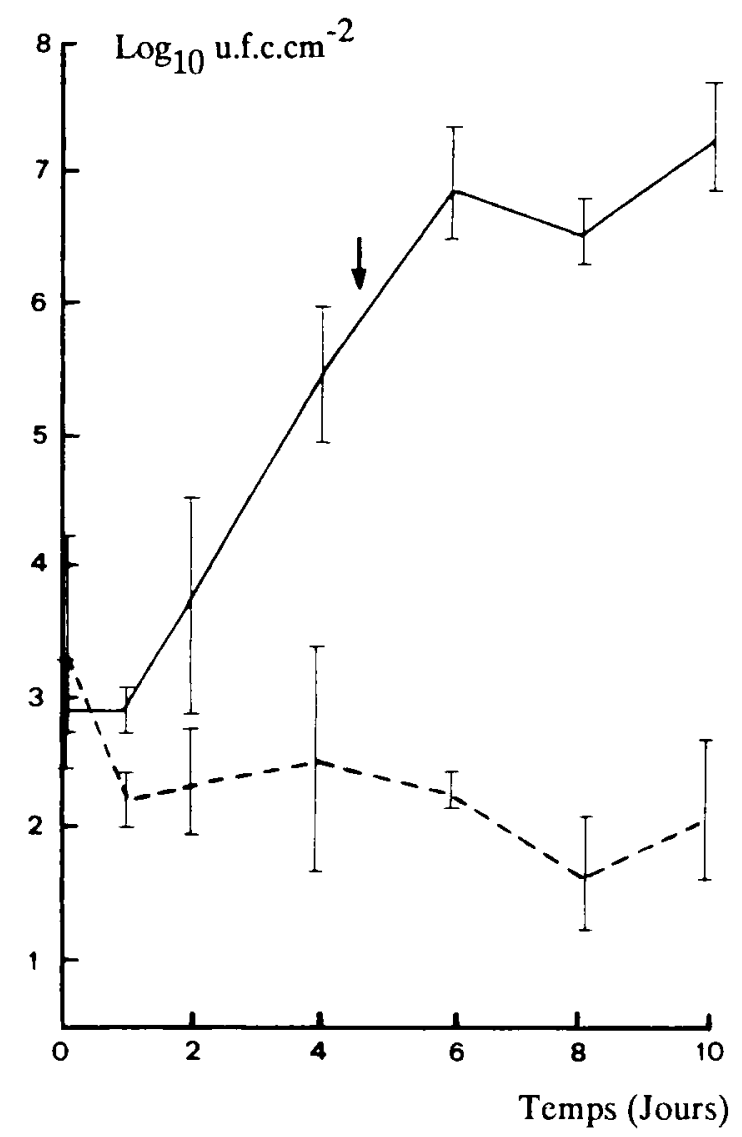

Fig 1. Dynamique de Xanthomonas campestris pv manihotis, souche agressive $\mathrm{XCM17}(-)$ et non agressive $\mathrm{XCM} 4$ $(---)$, à la surface des feuilles. Apparition des symptômes $(\rightarrow)$. I : écart type.

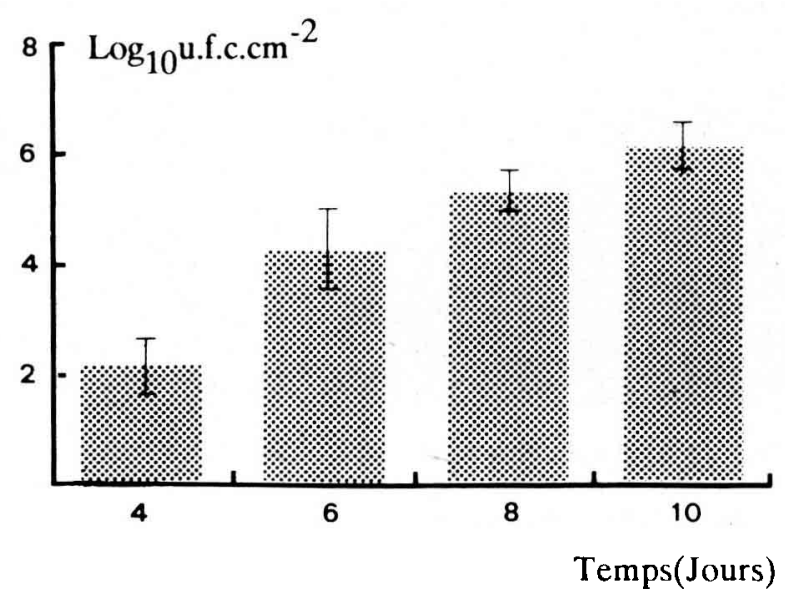

Fig 2. Évolution au cours du temps de la population bactérienne, souche agressive XCM17, à l'intérieur des feuilles. I : écart type.

cuticulaire plissé. Les stomates sont disposés le long des nervures principales et secondaires (fig 3).

A la face inférieure, les stomates sont répartis sur toute la surface du limbe et sont entourés de cellules digitées (fig $4 \mathrm{a}$ et $\mathrm{b}$ ).

Par la méthode du point critique, l'organisation des tissus est conservée mais la turgescen- 

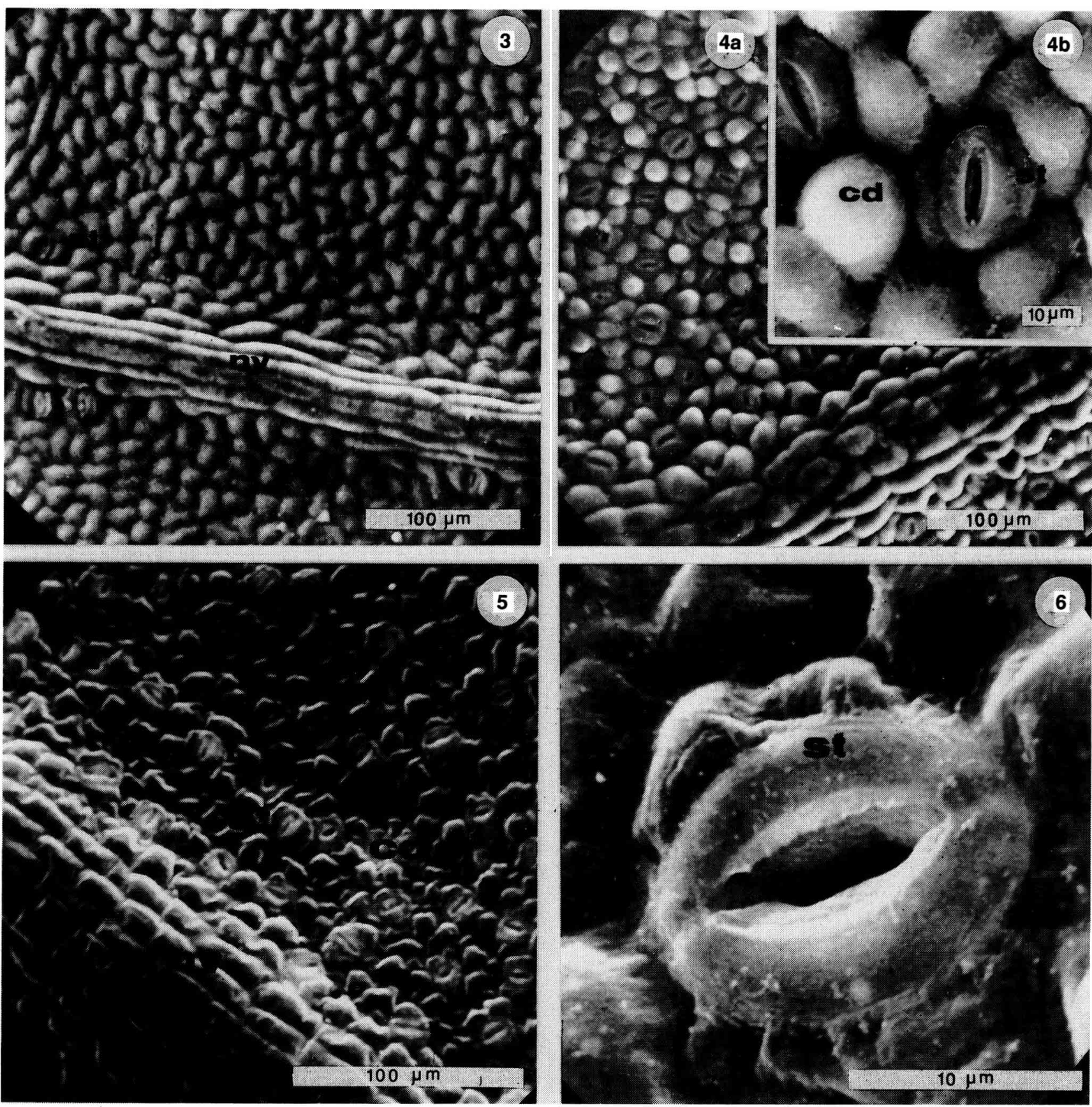

Fig 3 à 6. Morphologie des tissus sains de manioc préparés au cryoscan ou par déshydratation selon la méthode du point critique. nv : nervure ; st : stomate; cd : cellules digitées.

Fig 3. Cryoscan. Face inférieure du limbe.

Fig 4. a : Cryoscan. Face inférieure du limbe. b : agrandissement montrant un stomate entouré de cellules digitées.

Fig 5. Déshydratation selon la méthode du point critique. Face inférieure du limbe. Noter l'altération de la turgescence des cellules digitées et dans une moindre mesure du stomate.

Fig 6. Déshydratation selon la méthode du point critique. Stomate de la face inférieure du limbe. La déshydratation induit une déformation modérée des parois de l'ostiole.

ce des cellules épidermiques est altérée (fig 5 et 6).

Au cryoscan les tissus végétaux sont correctement préservés, mais les bactéries présentent des déformations et un affaissement qui rendent leur observation difficile (fig 7). Au contraire, par la méthode du point critique, la morphologie des bactéries paraît mieux conservée (fig 8).

\section{Répartition et évolution de la population bactérienne}

Immédiatement après inoculation, les 2 souches, isolées ou en groupes de quelques bactéries dispersées sur l'ensemble des cellules épidermiques, présentent une répartition identique (fig 9 et 10). L'observation à $2 \mathrm{j}$ n'apporte pas d'information supplémentaire. Six jours après inoculation, les clichés confirment l'augmentation 

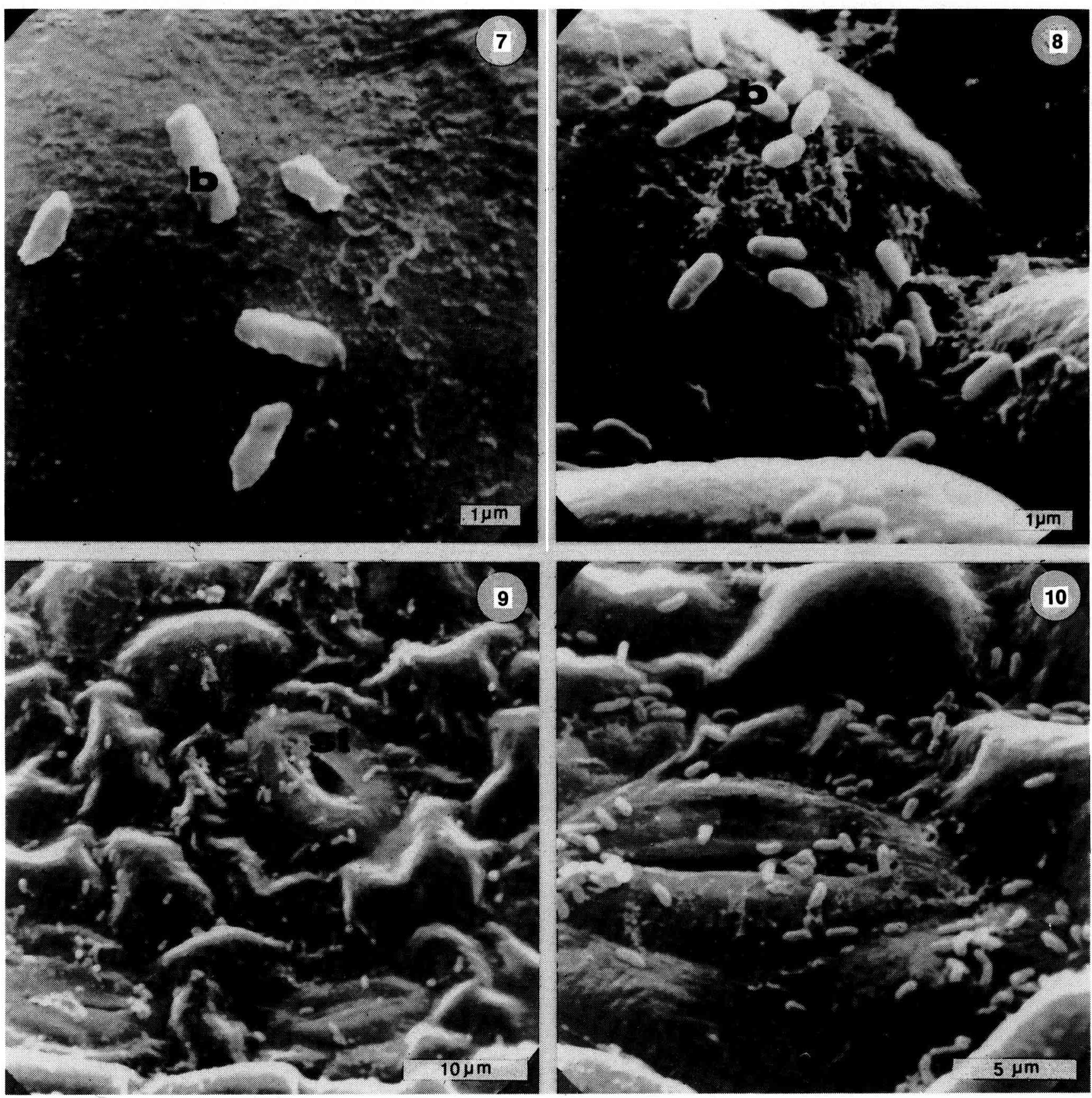

Fig 7 et 8. Aspect des bactéries (b) selon la technique de préparation employée.

Fig 7. Cryoscan. Les cellules apparaissent partiellement aplaties et déformées.

Fig 8. Point critique. La forme des bactéries n'apparaît pas modifiée.

Fig 9. et 10. Répartition des bactéries à la face inférieure du limbe de manioc, immédiatement après inoculation. Préparation des échantillons selon la technique du point critique. La répartition des bactéries apparaît homogène à la surface du limbe. $b$ : bactérie ; st : stomate.

de la population bactérienne uniquement pour la souche agressive (XCM17) et permettent de préciser sa localisation, en particulier au niveau des stomates (fig 11 et 12). Le cliché 13 montre des bactéries dans la chambre sous-stomatique. Elles sont regroupées en amas importants associant cellules et fibrilles (fig 14 et 15).

La souche non agressive (XCM4) ne se multiplie pas, les bactéries sont difficilement identi- fiables et apparaissent le plus souvent voilées par un composé de nature et d'origine indéterminées (fig $16 a$ et $b$ ).

\section{Aspect des tissus après inoculation}

Les tissus inoculés avec la souche non agressive ne présentent pas de modification de structure et de turgescence, quelle que soit la méthode utili- 

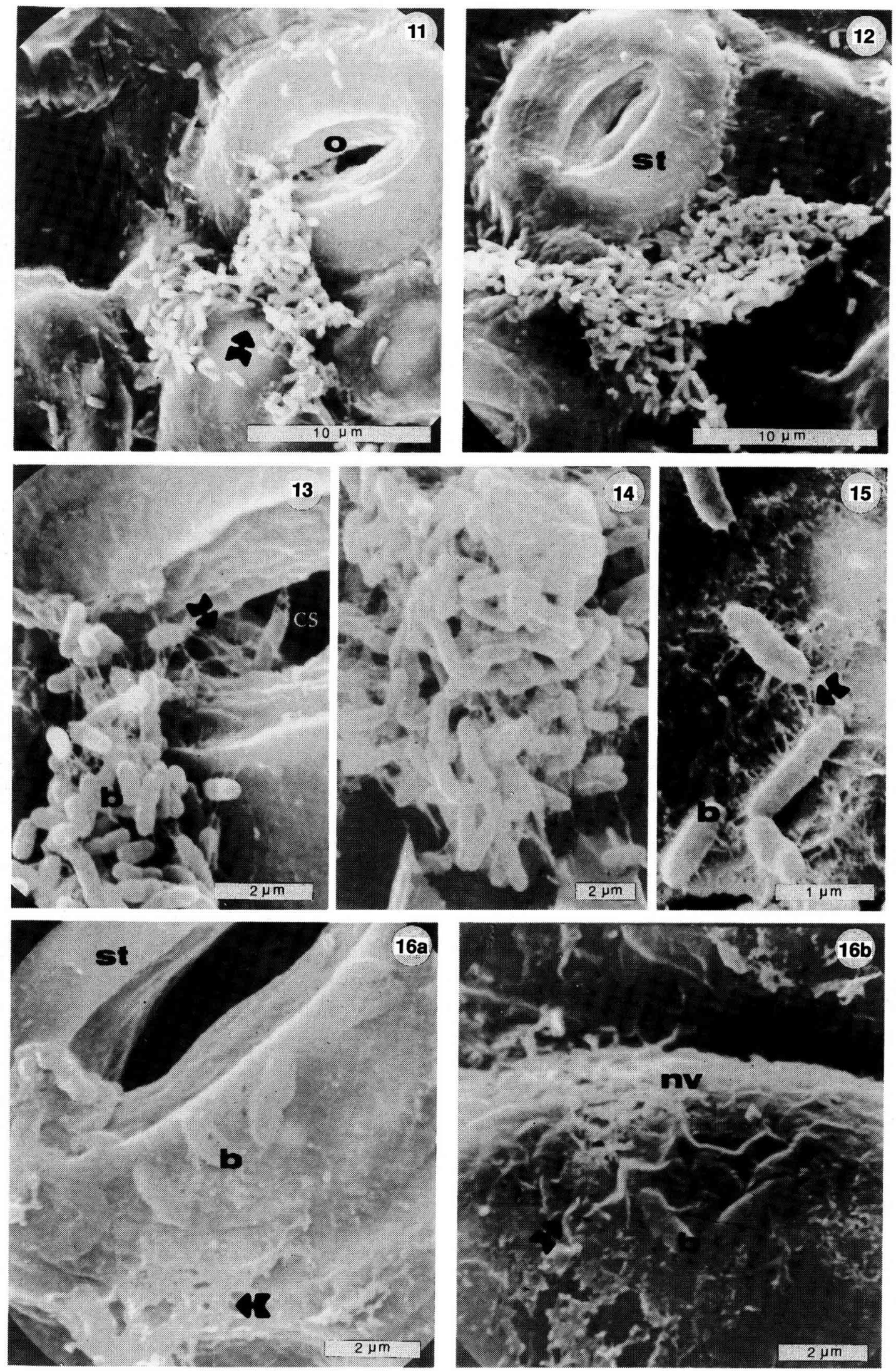

Fig 11 à 16. Observations des tissus préparés par déshydratation selon la méthode du point critique.

Fig 11. Amas bactérien $(\rightarrow)$ à proximité de l'ostiole (o) à la face inférieure. La prolifération des bactéries sur un côté de l'ostiole suggère un début de colonisation de la chambre sous-stomatique.

Fig 12. Concentration bactérienne $(\rightarrow)$ de la souche agressive (XCM17) dans les dépressions entourant un stomate (st) de la face inférieure du limbe de manioc $6 \mathrm{j}$ après inoculation. $a b$ : amas bactérien.

Fig 13. Détail de la colonisation bactérienne. Plusieurs bactéries (b) sont visibles $(\rightarrow)$ à l'intérieur de la chambre sous-stomatique (cs).

Fig 14. Détail d'une microcolonie bactérienne.

Fig 15. Cellules bactériennes (b) à la surface inférieure des feuilles. On note la présence de fibrilles reliant entre elles bactéries et surface foliaire $(\rightarrow)$.

Fig 16a et b. Souche non agressive (XCM4) à la face inférieure des feuilles 6 j après inoculation. Les bactéries (b) restent à l'état isolé ou groupées par 2 à 3 et sont recouvertes d'un composé de nature indéterminée $(\rightarrow)$. a : à proximité d'un stomate (st); b : sur la 
sée (fig $17 \mathrm{a}$ et b). Six jours après inoculation avec la souche agressive XCM17, les tissus sont très altérés et présentent des déchirures importantes. On note un affaissement des cellules épidermiques et des lésions au niveau de la cuticule (fig 18a et b, 19a et b).

\section{DISCUSSION}

La méthode classique d'analyse de population utilisée ici associée à l'observation microscopique permet de comparer le comportement d'une souche agressive et non agressive de $X c$ pv manihotis en condition d'axénie. La technique d'inoculation utilisée permet de reproduire les symptômes caractéristiques de la maladie avec la souche agressive et confirme que la souche non agressive n'entraîne aucune réaction décelable de la plante. Des résultats analogues ont été obtenus sur plantes en serre (Grousson, 1986).

L'application conjointe de 2 méthodes de préparation des spécimens (cryoscan et point critique) compense les altérations induites par l'une ou l'autre méthode sur la morphologie des bactéries et la structure des tissus végétaux. Une démarche comparable a déjà été employée pour d'autres études (Schmit, 1978) et son intérêt souligné par Petrolini et al (1986). La méthode du point critique n'est pas très favorable à l'observation des cellules végétales mais pourrait être améliorée en modifiant la molarité du tampon utilisé ou la durée de fixation des échantillons.

La souche agressive de $X c \mathrm{pv}$ manihotis (XCM17) trouve au cours de l'installation sur les feuilles de vitroplants des conditions favorables à une multiplication active et peut être détectée à des niveaux et dans des délais comparables à ceux établis dans le cas d'autres associations étudiées in vitro (Gardan et Pruvost, 1987). En revanche, la souche non agressive de $X c \mathrm{pv}$ manihotis (XCM4) se comporte comme une souche indifférente: absence de symptômes, maintien de la population à son niveau d'origine. Cette souche, pour des raisons non déterminées (déficiences nutritionnelles, sensibilité à des inhibiteurs), n'exprime pas ses capacités de multiplication bien qu'elle manifeste sur milieu artificiel une vitesse de croissance comparable à celle de la souche agressive.

L'examen microscopique confirme la différence fondamentale entre le niveau de population des 2 souches, la répartition et l'aspect des bactéries. Pour la souche non agressive, l'observation d'un nombre réduit de cellules bactériennes dispersées par 2 ou 3 est en accord avec l'ab- sence de multiplication à la surface des feuilles. Nos résultats confirment les observations en immunofluorescence de Daniel et Boher (1981) montrant le regroupement fréquent des bactéries en petits amas, préférentiellement situés à la face inférieure dans les dépressions du limbe avoisinant les nervures et les cellules digitées de l'épiderme. Cette étude montre la présence de microcolonies (souche agressive) colonisant préférentiellement les abords des stomates, de l'ostiole et de la chambre sous-stomatique. Des observations comparables ont été faites sur des feuilles de pêcher infectées par Xanthomonas campestris pv pruni (Miles et al, 1977) et sur feuilles de concombre inoculées avec Pseudomonas syringae pv. lachrymans (Yamanaka et al, 1980). Nous avons constaté un déroulement comparable de l'infection avec des sites préférentiels de multiplication, sans mettre en évidence une extrusion ostiolaire aussi abondante que celle observée par Miles et al (1977).

Toutefois, à un stade plus avancé, la poursuite d'une multiplication intense dans la chambre sous-stomatique pourrait aboutir aux figures d'extrusion décrites ailleurs. Dans le cas étudié, la forme des amas et leur localisation suggèrent plutôt une invasion de proche en proche, invasion qui peut se traduire aussi bien par une intrusion que par une extrusion ostiolaire. Une prolifération des bactéries dans la chambre sousstomatique pourrait être l'origine de l'infection des parenchymes et des tissus vasculaires. Un tel système in vitro, où les blessures d'origine extérieure sont contrôlées, offre d'ailleurs d'intéressantes possibilités d'étude pour cette étape.

Comme le soulignent Miles et al (1977), Yamanaka et al (1980) ainsi que Roos et Hattingh (1983), les amas bactériens accumulés à la surface du limbe seraient des sources supplémentaires d'inoculum.

Nos travaux montrent que la souche agressive est associée à une structure fibrillaire comparable à celle observée dans les cavités stomatiques infectées par Pseudomonas syringae pv morsprunorum (Roos et Hattingh, 1983). Avec la souche non agressive, nous avons mis en évidence l'existence d'une structure non fibrillaire voilant l'inoculum dispersé sur l'épiderme. Ces observations sont à rapprocher de celles faites par Mew et al, 1984, dans le cas de bactéries avirulentes de Xanthomonas campestris pv oryzae à la surface des feuilles de riz.

Sans présumer du mécanisme en cause, on peut rapprocher ces observations de celles effectuées, en microscopie électronique par transmission, à l'intérieur des tissus, par Sequeira et al, 1977, Sing et Schroth, 1977, Jones et Fett, 1985. 

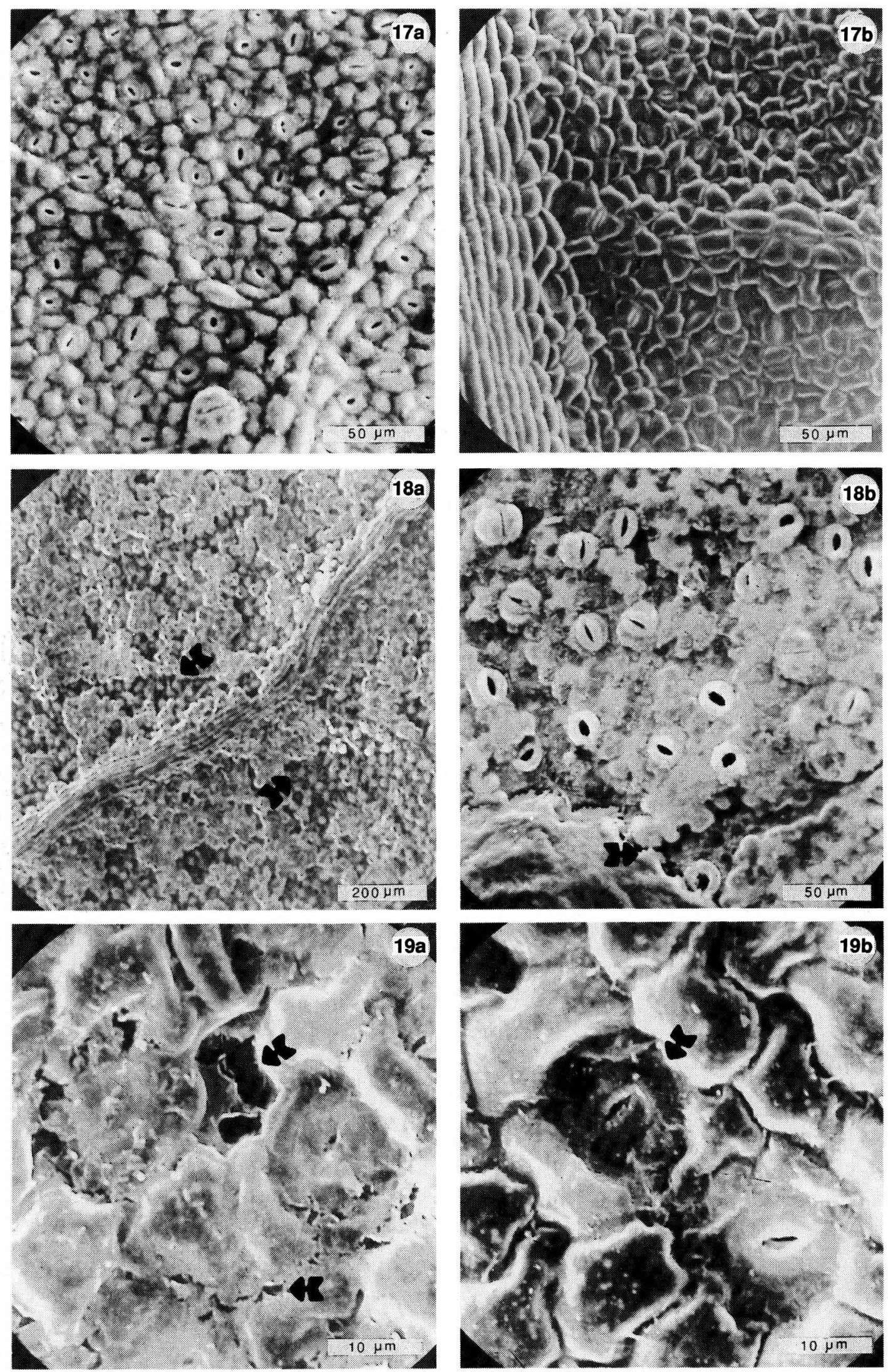

Fig $17 a$ et $b$. Morphologie des tissus infectés par la souche non agressive XCM4, face inférieure des feuilles $6 \mathrm{j}$ après inoculation. On n'observe pas d'altération marquée des tissus (voir par comparaison les photos 18a, 18b et 19a, 19b). a : tissus observés au cryoscan ; b : tissus traités par la méthode du point critique. Les cellules épidermiques apparaissent moins turgescentes.

Fig 18a et b. Morphologie des tissus de la face inférieure du limbe après 6 j d'infection, par la souche agressive (XCM17). a : déshydratation par la méthode du point critique; b : observation au cryoscan. On observe un collapsus des premières assises cellulaires $(\rightarrow)$. Ces régions correspondent aux premiers symptômes décelables à l'observation visuelle.

Fig 19a et b. Agrandissement au niveau d'une lésion, 6 j après inoculation par la souche agressive (XCM17), face inférieure du limbe, tissus préparés selon la méthode du point critique. $\mathbf{a}$ : on note des déchirures de l'épiderme $(\rightarrow) ; \mathbf{b}$ : affaissement des cellules stomatiques $(\rightarrow)$. 


\section{CONCLUSION}

Notre étude confirme la place accordée à la colonisation des stomates et de leurs abords pour le développement et la dissémination de l'infection par les bactéries phytopathogènes épiphylles (Miles et al, 1977 ; Bashan et al, 1981; Huang, 1986) bien que Mew et al (1984) ainsi que Mansvelt et Hattingh (1987) aient fait remarquer que cette colonisation n'était pas toujours déterminante. Le regroupement des bactéries agressives en amas associés par un matériel fibrillaire s'observe également dans d'autres cas d'infections. II s'apparente aux formations décrites en bactériologie médicale, vétérinaire et végétale pour d'autres couples hôtes-pathogènes et pour des tissus physiologiquement différents (Mathysse et al, 1982 ; Costerton et al, 1987). De tels aspects semblent caractériser les réactions homologues et les différencient nettement des réactions observées pour les souches non agressives.

Le système expérimental adopté révèle bien ces différences dans le cas du manioc. Pour d'autres associations: Xanthomonas ampelinavigne (Ride et Bouquet, 1987), Erwinia amylovora-pommier (Paulin et Duron, 1986), I'utilisation de systèmes expérimentaux simplifiés (vitroplants, cals) permet d'identifier les souches bactériennes d'après leurs caractéristiques de pouvoir pathogène. La microscopie électronique confirme qu'il existe dans le cas présent une corrélation entre agressivité et colonisation.

On peut conclure que le système utilisé est adéquat pour juger du pouvoir pathogène des souches de $X_{C} \mathrm{pv}$ manihotis (sauvages ou construites) tout en tenant compte du fait que le critère de colonisation épiphylle n'est pas obligatoirement corrélé à l'induction de symptômes. En outre, ce système permet une approche simplificatrice certes mais pratique pour l'évaluation du comportement variétal, et peut trouver sa place, comme dans le cas d'autres études, dans les différentes étapes de sélection de plantes résistantes aux maladies (Ingram, 1980; Daub, 1986 ; Hammerschlag, 1988).

\section{REMERCIEMENTS}

Les auteurs remercient Mlle J Berrier (INRA, laboratoire des sciences du sol, Versailles), de sa collaboration et de son assistance technique pour les observations en microscopie électronique. Nous remercions M B Boher et M JF Daniel (Centre ORSTOM, Brazzaville, Congo) pour leurs conseils lors de la mise au point des tests sur vitroplants et MM P Ndongo et M Levy (Centre ORSTOM, Brazzaville), pour leur assistance technique.

\section{RÉFÉRENCES}

Bashan, Y, Sharon E, Okon J, Henis Y (1981) Scanning electron and light microscopy of infection and symptom development in tomato leaves infected with Pseudomonas tomato. Physiol Plant Pathol 19, 139-144

Boher B, Daniel JF (1982) Étude de la localisation de Xanthomonas campestris pv manihotis agent de la bactériose vasculaire dans les tiges de manioc (Manihot esculenta Crantz). Rapport ORSTOM, Brazzaville, République Populaire du Congo, $8 p$

Brisset MN, Paulin JP, Duron M (1988) Feasibility of rating fire blight susceptibility of pear cultivars (Pyrus communis) on in vitro microcuttings. Agronomie 8, 707-710

Costerton JW, Cheng KJ, Geesey GG, Ladd TI, Nickel JC, Dasgupta M, Marrie TJ (1987) Bacterial biofilms in nature and disease. Ann Rev Microbiol 41, 435464

Daniel JF, Boher B (1978) Ecology of cassava bacterial blight : epiphytic survival of Xanthomonas campestris pv manihotis on aerial parts of the cassava plant. In: Proceedings 4th International Conference Plant Pathol Bact, Angers, 763-771

Daniel JF Boher B (1981) Fluorescent antibody technique for detection of Xanthomonas campestris pv manihotis on cassava leaves. In: Proceedings 5th International Conference Plant Pathol Bact, Cali, 176-180

Daniel JF Boher B (1985) Epiphytic phase of Xanthomonas campestris pv manihotis on aerial parts of cassava. Agronomie 5, 111-116

Daub ME (1986) Tissue culture and the selection of resistance to pathogens. Ann Rev Phytopathol 24, 159-186

Gardan L, Pruvost $O$ (1987) Utilisation de vitroplants de noisetier pour l'étude de la vie épiphylle de Xanthomonas campestris pv corylina. In : Résumés $32^{\circ}$ colloque de la Société française de phytopathologie, Angers 14-15 mai 1987

Grousson F (1986) Variabilité de Xanthomonas campestris $p v$ manihotis. Thèse de Docteur Ingénieur, INA, Paris, $142 \mathrm{p}$

Hammerschlag FA (1988) Screening peaches in vitro for resistance to Xanthomonas campestris pv pruni. J Amer Soc Hort Sci 113, 164-166

Huang JS (1986) Uitrastructure of bacterial penetration in plants. Ann Rev Phytopathol 24, 141-157

lita (1983) Annual report. Ibadan, Nigeria 107-138

Ingram DS (1980) Tissue culture methods in plant pathology. In: Tissue culture methods for plant pathologists. (Ingram DS, Helgeson JP eds), Blackwell Scientific Publications, Oxford, 3-9

Jones SB, Fett WF (1985) Fate of Xanthomonas campestris infiltrated into soybean leaves: an ultrastructural study. Phytopathology 75, 733-741

Kwage CL (1982) Bacterial blight on cassava. FAO, Plant Prot Bull 30, 82-83

Lozano JC, Sequeira L (1974) Bacterial blight of cassava in Colombia : etiology. Phytopathology 64, 74-82

Maas JL, Finney MM, Civerolo EL, Sasser M (1985) Association of an unusual strain of Xanthomonas campestris with apple. Phytopathology 75, 438-445 
Mabanza J, Jonard R (1981) La multiplication des clones de manioc (Manihot esculenta Crantz) à partir d'apex isolés in vitro. CR Acad Sci 292, Sér III, 839-842

Mansvelt EL, Hattingh MJ (1987) Scanning electron microscopy of colonization of pear leaves by Pseudomonas syringae pv syringae. Can $J$ Bot 65 , 2517-2 522

Mathysse AG, Holmes KV, Gurlitz RHG (1982) Binding of Agrobacterium tumefaciens to carrot protoplasts. Physiol Plant Pathol 20, 27-33

Maraite M, Weyns J, Yinkwan O, Lipemba P, Perreaux $D$ (1981) Physiological and pathogenic variations in Xanthomonas campestris pv manihotis. In: Proceedings International Conference Plant Pathol Bact Cali, 358-368

Mew TW, Mew JC, Huang JS (1984) Scanning electron microscopy of virulent and avirulent strains of Xanthomonas campestris pv oryzae on rice leaves. Phytopathology 74, 635-641

Miles WG, Daines RH, Rue WJ (1977) Presymptomatic egress of Xanthomonas pruni from infected peach leaves. Phytopathology 67, 895-897

Murashige T, Skoog F (1962) A revised medium for rapid growth and bioassay with tobacco tissue culture. Physiol Plant 15, 473-497

Paulin JP, Duron M (1986) Inoculation of callus of root tissues of Malus domestica cv Golden Delicious for the identification of pathogenic strains of Erwinia amylovora (Burr) Winslow. Agronomie 6, 869-872

Perreaux D, Maraite H, Meyer J (1978) Histo-pathological study by fluorescent microscopy of cassava stems infected by Xanthomonas manihotis. In: Proceedings 4th International Conference Plant Pathol Bact, Angers, 935-941

Persley GJ (1978) Epiphytic survival of Xanthomonas manihotis in relation to the disease cycle of cassava bacterial blight. In: Proceedings 4th International Conference Plant Pathol Bact, Angers, 773-777

Petrolini B, Quaroni S, Saracchi M (1986) Scanning electron microscopy investigations on the relation- ships between bacteria and plant tissues: I. Comparative techniques for specimen preparation. Riv Pathol Veg S IV, 22, 7-15

Ride $M$, Bouquet A (1987) Variabilité de la réponse de Xanthomonas ampelina (Panagopoulos), agent de la nécrose bactérienne, de plants de vigne cultivés in vitro. In: Rés Comm $32^{\circ}$ Colloque SFP, Angers, 14-15 mai 1987

Roos JMM, Hattingh MJ (1983) Scanning electron microscopy of Pseudomonas syringae pv morsprunorum on sweet cherry leaves. Phytopathol Z 108, 18-25

Rott P, Chagvardieff $P$ (1987) In vitro reactions of sugarcane (Saccharum sp.) plantlets inoculated with two strains of Xanthomonas albilineans (Ashby) Dowson. Plant Cell Tissue Organ Cult 9, 9-18

Sequeira L, Gaard G, De Zoeten GA (1977) Interaction of bacteria and host cell walls: its relation to mechanisms of induced resistance. Physiol Plant Pathol $10,43-50$

Schmit $J(1978)$ Microscopic study of early stages in infection by Pseudomonas solanacearum EFS on in vitro grown tomato seedlings. In: Proceedings 4th International Conference Plant Pathol Bact Angers, 841-856

Schwartz D (1969) Méthodes statistiques à l'usage des médecins et des biologistes. Flammarion, médecine-sciences, Paris $3^{\circ}$ éd, $318 p$

Sing VO, Schroth MN (1977) Bacteria plant cell surface interactions: active immobilization of saprophytic bacteria in plant leaves. Science 197, 759-761

Verdier V (1988) Contribution à l'étude de la variabilité de Xanthomonas campestris pv manihotis (Arthaud Berthet et Bondar) Starr, agent causal de la bactériose vasculaire du manioc (Manihot esculenta Crantz). Thèse de Doctorat, Orsay, $n^{\circ} 528,261 p$

Yamanaka S, Ozaki M, Kato S (1980) Some observations on angular leafspot of cucumber with a scanning electron microscope. Tohoku J Agric Res 30 , 135-141 